\title{
19 Research on intuition using intuition
}

\author{
Viktor Dörfler and Colin Eden
}

About a century ago Henri Bergson $(1911,1946)$ argued that intuition is a necessary component of philosophical inquiry, and indeed of any enterprise that seeks to understand a complex thought. To us, it therefore makes sense that, in Bergson's framework, intuition is necessary for researching intuition. Like Bergson, we do not suggest that now we should start using intuition in our research - rather, we suggest that we acknowledge that we have always been using it. Of course, this is an argument with hindsight, based on experiences from our empirical study of Nobel Laureates (NLs).

In this research project, underlying the methodological argument presented here, we conducted unstructured interviews with a set of individuals who would be acknowledged as experts by the 'world at large': those awarded the highest accolade of the Nobel Prize. ${ }^{1}$ We were not explicitly aiming at exploring the intuition of NLs, but more generally their cognitive complexity. From this inquiry, intuition has emerged as a significant characteristic of the NLs' thinking. It is of particular interest that, although we have not decided ex ante on an intuitive approach, it emerged naturally as we were trying to make sense of the interviews. Based on this inquiry, we seek to revive Bergson's interest in intuiting, and argue for the renewed importance of intuition as a method in academic research in the field of management and organizations.

\footnotetext{
${ }^{1}$ We have been focusing on people obtaining the highest prize in their respective professions; 17 out of the 19 interviewees were Nobel Laureates but there have also been two computer scientists who have been awarded the Eckert-Mauchly prize. For simplicity, when referring to all our interviewees, we call them Nobel Laureates.
} 
In this chapter we use the term intuition in a broad sense, what, based on Behling and Eckel (1991) and Osbeck (2001), Sinclair (2011) describes as 'direct knowing'. Vaughan (1979) explains this view of intuition in terms of knowing without knowing how, or, in the spirit of Agor's (1986) view, knowing for sure without knowing for certain. In a sense, this is the essence of the conceptualization of intuition as 'direct knowing' - knowledge is not arrived at by the analytical step-by-step methods usual in the academic publications and, at the time when it is obtained, there is no evidence of it being right.

In what follows we first present a brief overview of what the scholarly literature on management and organizations has to say about the intuiting of practising managers. Then, we revisit scientists' intuiting, partly based on literature from history and philosophy of science and partly using example quotes from the interviews in the NL project. This outline begs the question: if intuition is accepted in the case of practising managers and of scientists, why it is not accepted in the case of scholars who are studying the intuition of those managers and scientists? Thus, we continue our chapter by offering some tentative answers to this question, with the aim of being thought-provoking and so prompting further discussion. Finally, we

present our methodological approach, which explicitly incorporates intuition rather than denying it.

\section{INTUITION OF MANAGERS}

In the literature on management and organizations it was Chester Barnard (1938: 291) who first assigned crucial importance to the intuition of executives, and argued that intuition is 'nowhere more indispensable than in executive arts'. In spite of the large number of studies reporting on the intuition of practising managers (e.g., Dean \& Mihalasky, 1974; Ford, 1977; Isenberg, 1984; Mintzberg, 1976; Peters \& Waterman, 1982) and a couple of 'wake-up calls' 
emphasizing the importance of the topic (e.g., Isaack, 1978; Leavitt, 1975; Simon, 1987), the notion of intuition was not fully explored systematically in the mainstream academic literature on management and organizations until recently (e.g., Akinci \& Sadler-Smith, 2012; Dane \& Pratt, 2007, 2009; Gore \& Sadler-Smith, 2011; Hodgkinson et al., 2008, 2009; Kahneman, 2003; Sinclair \& Ashkanasy, 2005).

This recent rejuvenation of interest in intuition in the academic literature on management and organizations has not yet resulted in a unified framework (Sinclair, 2011). However, there is substantial agreement about the fundamental features of intuition (e.g., Dane \& Pratt, 2007; Kahneman, 2003: 698; Sadler-Smith, 2008: 13). Three of these features apply to the process of intuiting and three to the outcome of such a process - the intuitive knowledge. Intuiting is rapid (often labelled instantaneous), spontaneous (does not require effort and cannot be deliberately controlled) and alogical (meaning that it does not necessarily contradict the rules of logic but also does not follow them). The outcome of the intuitive process is tacit (in that intuitors cannot give an account of how they arrived at the results), holistic (also often called gestalt as it is concerned with the totality of a situation rather than parts of it), and the intuitor feels confident about their intuition (with no apparent reason in terms of evidence). Most authors also agree about strong relations to affect. However, there are still numerous studies being published on identifying and/or classifying types of intuition (e.g., Dane \& Pratt, 2009; Dörfler \& Ackermann, 2012; Gore \& Sadler-Smith, 2011), which is why the conceptual debates still continue even if most authors agree that it is time to focus on empirical research (Sinclair \& Coget, 2011).

As with any other concept or ability or technique, intuition is not a 'super-tool' for effective decisions and problem solving that is always applicable, in every situation, by everyone, and without constraints. Successful managers predominantly use their intuition when time is short, when there is no sufficient information for formal deliberate analysis and so forth (see, e.g., 
Dane \& Pratt, 2007; Sinclair \& Ashkanasy, 2005). As may be expected, there are authors who argue for and against whether managers should use intuition. However, those who cite experimental evidence about the failure of intuition mostly study intuition of novices, while those who found intuition beneficial are focused on experts' intuition (for more details, see Dörfler \& Ackermann, 2012: 549-550). Currently, there seems to be considerable agreement that only the intuition of people with a high level of expertise, such as NLs, is worthy of trust (Hogarth, 2001; Kahneman \& Klein, 2009; Prietula \& Simon, 1989; Salas et al., 2010).

\section{INTUITION OF SCIENTISTS}

When examining the thinking process of philosophers, Bergson (1946) concluded that no complex thought can be arrived at other than by means of intuiting. He saw the role of intuition (Bergson, 1911: 238-239) as important for arriving at new ideas, after which we should abandon intuition and then work on building the body of knowledge using the new intuitively obtained knowledge. When we begin to 'feel lost', he argued that we should get in touch with our intuition again, often undoing what we have done in the deliberative phase, and continue this process in cycles. Thus, Bergson (1946: 33) argued for intuition as part of a method, particularly in areas of complex, dynamic and abstract thinking. Our findings provide significant support for this assertion; for the NLs we have investigated, no significant research result has been achieved without intuition playing a major part in the process. This result is also consistent with Popper's (1968: 8) view that 'there is no such thing as a logical method of having ideas, or a logical reconstruction of this process ... every discovery contains ... "a creative intuition", in Bergson's sense'. Bruner (1966: 2), who originally built up his reputation in mainstream psychology, arrived at a similar conclusion: 'Reaching for knowledge with the right hand is science. Yet to say only that much of science is to overlook one of its excitements, 
for the great hypotheses of science are gifts carried in the left hand.' Furthermore, he emphasizes (Bruner, 1977: 67) that it is usually the most esteemed scientists who earn the label of 'intuitive', which in itself is strong evidence that scientists find intuition valuable. This strong evidence for the use of intuition in research from the philosophy of science is further strengthened by numerous stories from the history of science (e.g., Beveridge, 1957; Hadamard, 1954; Hong, 2006b; Poincaré, 1914; Polányi \& Prosch, 1977).

Notably, in our research, we found no counter-examples where a NL denied using intuition or did not provide examples of intuition being used. Those who did not use the term intuition describe their work in terms remarkably similar to those we used to describe intuition above. Indeed, many of our interviewees preferred to avoid the term intuition in order to avoid the implication of lay and mystical explanations, but they did describe expert intuition at work (cf. 'experiential approach' by Klein \& Weick, 2000). They often described it as 'just knowing', as Kenneth Arrow (NL in Economics 1972), talking about helping his disciples choose their research directions, commented:

Well, of course obviously my job is to tell them ... I can see this isn't going to work, either because somebody else has done it or because I can just see it doesn't work.

Similarly, Yoichiro Nambu (NL in Physics 2008) described intuition as a kind of intellectual feeling:

Something that's clicked in my mind, that seems interesting or something that's maybe promising that's a kind of feeling I have.

James Cronin (NL in Physics 1980), when talking about how much he based his scientific problem solving on intuition, said: 
[on using intuition in his research] Oh, I think quite a bit. I don't know if intuition or ... you build up over the years of experience, and you kind of have a sense of what's going to work and what's not going to work. Intuition, yeah, I guess so, but you know intuition again is one of these things a little bit hard to define exactly ...

So, for these scientists, what we would call intuition is the 'big leap' that takes them to the start of the solution and the continued development of it. The 'big leap' notion of intuition is not limited to scientists. Davenport and Prusak (2000: 11) use a very similar description in their popular book on knowledge management: 'We arrive at an answer intuitively, without knowing how we got there. That does not mean the steps to not exist - intuition is not mystical. It means we have so thoroughly learned the steps that they happen automatically, without conscious thought, and therefore at great speed' (emphasis added). This resonates with Gauss's account of a solution to a long-standing problem he obtained through intuitive insight (Hong, 2006a: 144): 'The riddle solved itself as lightning strikes, and I myself could not tell or show the connection between what I knew before, what I last used to experiment with, and what produced the final success.' More generally about his findings, he says (Polányi, 1962: 131): 'I have had my solutions for a long time but I do not yet know how I am to arrive at them.'

\section{INTUITION IN MANAGEMENT AND ORGANIZATION RESEARCH}

Thus, intuition is accepted as a valid contributor to the generation of knowledge by researchers in the field of science and also accepted as an integral part of being an effective manager. However, in management and organization research are we rejecting, or hiding, its role? In management and organization research Eisenhardt (1989: 532) has suggested that 'frame 
breaking insights, the testing of a good theory (e.g., parsimony, logical coherence), and convincing grounding in the evidence are key criteria for evaluating this type of research'. Intuition is one way of providing the frame breaking insights. However, the role of intuition has been denied as being 'at the heart of qualitative analysis for far too long' (Lee \& Lings, 2008: 252-253). Thomas (2004: 38) emphasizes that we only assume that intuition arises from unconscious processes, and if it yields insight we accept it as valuable. In comparison, Polányi (1962: 16) notes that the traditional conception of objective sciences 'would be shattered if the intuition of rationality in nature had to be acknowledged as a justifiable and indeed essential part of scientific theory'. As Tsoukas (2005: 142) argues, we mistrust intuitive knowledge obtained through ad hoc or, at least, less defined practices in favour of explicit knowledge obtained through well-defined, if possible standardized, procedures.

Management and organization research is not alone in this apparent negative approach to the role of a researcher's intuition. As Bruner (1977: 66) indicated: 'one hears the most explicit talk about intuition in those fields where the formal apparatus of deduction and induction is most highly developed'. If we assume that researchers in the area of management and organizations are similar to researchers in other fields, we must assume that the intuitionanalysis cycle is present in our research as well. However, as we suggest above, this is virtually never acknowledged explicitly. Perhaps we avoid reporting on the role of intuition because we are ashamed of its significance, perhaps because we do not allow for it to influence our research, perhaps because we expect it to be seen as improper - untidy, unsystematic - by our peers. If the role of intuition were discussed in papers submitted to top journals in the management and organizations field, then we expect that the papers would be rejected because of the declared difficulty of replication.

If an intuitively obtained insight needs to be justified in, e.g., physics or chemistry, it can be expected that the analytical explanation is completely rigorous. In contrast, 'management 
theories are more complex and, hence, more difficult to structure in a way that is scientifically testable with any degree of clarity' (Devinney \& Siegel, 2012: 6), which may be another reason for not admitting intuition. This resonates with the argument put forward by Corley and Gioia (2011: 15) that business schools 'began to emphasize more rigorous, quantitative orientations in an attempt to gain legitimacy within the larger academic community' and in doing so, we fail to generate theories that could 'generally be seen as more interesting and, thus, more likely to make an impact on the reader'. In any event, we may be discouraging the potential for 'big leaps' in our research by not admitting it either in practice or in reporting our research.

More generally, Einstein remarks that: 'The intuitive mind is a sacred gift and the rational mind is a faithful servant. We have created a society that honors the servant and has forgotten the gift' (quoted by Klein, 2004: 3). We are suggesting in this chapter that it is appropriate and helpful to use intuition, and to admit its role, and not forget the gift.

\section{THE EMERGENT ‘INTUITIVE’ METHOD OF THE NOBEL LAUREATES PROJECT}

In our research on the cognitive complexity of NLs we did not decide in advance on the methods we intended to apply for the analysis of our interview data. We started the process of analysis by experimenting with alternative ways of making sense of the rich qualitative data obtained from the interviews. Gradually, 'a method' started to emerge, which we believe has proved to be helpful in revealing some characteristics of the thinking of NLs. Among these characteristics was a dominance of intuitive thinking as being particularly salient. We see our method, which explicitly incorporates the intuition of the researcher, as a valid way of research trying to understand intuition better.

The conceptual framework informing our empirical study of NLs is a model of knowledge levels (Dörfler et al., 2009). On the basis of this model, we became increasingly interested in 
the cognitive complexity of people at the highest level of knowledge. The methodological approach that we adopted (Dörfler \& Stierand, 2009) focuses on the notion of 'extraordinary' people: those who are positive outliers of the population in terms of the phenomenon being investigated. This essentially means that we believe that we can learn the most about the development of new knowledge through examining people generally acknowledged to be at the highest level of research prowess, and NLs are arguably exemplars of this. Although there are undoubtedly a very large number of people as well as NLs who would be regarded as being at those levels, it did at least seem indisputable that NLs were at the top of their field.

Investigating the extraordinary is not typical in academic research but it is also not without precedence, the most notable examples include Maslow (1970, 1971), Csíkszentmihályi (1997, 2002) and Gardner (1993, 1995, 1997). We have also discussed our research project with the latter two researchers, and these discussions served for fine-tuning our approach. Csíkszentmihályi, for instance, claims that he spent years trying to apply various structured and semi-structured ways of analysing his 91 interviews with extraordinary creative people and he failed. Finally, he decided to simply write about what he learned during these interviews and provide examples - which, finally, is the approach we chose to start with.

In order to enable the collection of the richest data, we chose to use relatively unstructured interviews from the outset. Naturally, the earlier interviews inevitably informed the later ones, but we deliberately tried to keep the interviews as open as possible - simply to have meaningful conversation with the interviewees on any topic they wanted to talk about with respect to their approach to research - to let salient characteristics naturally emerge. We need to note here, that our approach is different from grounded theory (Glaser, 1992; Glaser \& Strauss, 1967) as we did not aim for openness in the sense of starting with an 'empty slate', but for a well-informed openness. The interviewer (Viktor) learned in advance as much as possible both about the research and personal histories of the interviewees. There are similarities to grounded theory 
in terms of analysing the interviews, as we have been looking for emergent properties and tried be open-minded. However, the focus of the analysis, as we describe below, is the changed understanding of cognitive complexity - which presupposes rather than denies/disregards previous knowledge.

The average interview length was more than one hour and the 19 interviews resulted in around 400 pages of transcript and a few dozen pages of field notes. In addition, we researched the background of our interviewees from nearly 400 publicly available sources, including about 20 hours of video material, adding over 300 pages of text. Simply looking at the large amount of text (transcripts and notes) was regarded as far too restrictive in comparison with the actual experience of the interviews (capturing the non-verbals and gestalt). Trying to preserve as much as possible of this richness, we started conversations between the two researchers (the interviewer - Viktor - and other - Colin) trying to make sense of what we have learned about the cognitive complexity of NLs and the following process emerged.

\section{Unstructured Interviews on Unstructured Interviews}

Viktor conducted all the interviews and Colin, without reading the transcripts, started an interview-like process trying to figure out what sense Viktor made of the interviews. In the first two sessions (about 5 hours each) this was done in the form of free conversation, the focus was on the 'big picture' rather than the particular interviews and was largely driven by an exploration of what was surprising and interesting, including 'critical incidents' (Bryson et al., 1996; Flanagan, 1954; Gremler, 2004). Typical questions were: 'How would you now argue that these interviews were with people at the highest level of expertise?' or 'What do we learn from these interviews about difference between the highest and the penultimate levels of expertise? What would be the 'break-point'?' These first two meetings resulted in a number of possible emergent themes as Colin sought to make sense of responses of Viktor's reportage from a holistic stance. 


\section{Concept Mapping}

In the third and fourth sessions (over 6 hours each) Colin developed several concept maps (Bryson et al., 2004; Eden, 1992; Hodgkinson et al., 2004; Huff, 1990) about the issues that emerged in Viktor's intuitive understanding of the highest level of knowledge using causal mapping software (Decision Explorer, $\mathrm{DE}^{2}$ ). These sessions resulted in several concept maps following the discussions from various perspectives. The maps were constructed interactively and in real time during the discussions. As the maps unfolded they were crudely analysed 'slicing' the maps in many different ways to explore emergent clusters and structures (Eden, 2004). These analyses were informed by the focal points from the first stage but did not strictly follow them, so additional themes emerged.

\section{Coding}

In the next stage the concepts and themes from the DE maps were transferred as nodes into NVivo. ${ }^{3}$ Here the process was similar to the typical use of NVivo, the difference being in the source of the coding nodes. The coding started using the concepts identified in the DE maps but the coding process was open, allowing for new nodes that emerged during the processing. Apart from a few examples, when some coding nodes have been already identified in the DE maps as variants or cases of a more general concept (e.g., four versions of the node 'masterapprentice relationship'), the nodes have not been structured. Thus, NVivo was used as a part of substantiating the emergent properties from the researcher discussions and the maps developed through them (in the same way, discussed above, that intuition guided deep analysis, and cycled back to intuition).

\section{Iterative Cycles}

2. Decision Explorer is software designed to display and analyse concept/causal maps (http://www.banxia.com/dexplore/).

3. NVivo is software designed to facilitate content analysis (http://www.qsrinternational.com/). 
The cycle continued as newly emergent nodes were transferred from NVivo back to the previously created concept maps and new maps were created through the continual modification of the old maps. Here, through further interviews between the researchers, additional concepts emerged that were, in turn, added to NVivo again. Breaking up these 'shorter' cycles, further unstructured meetings of the researchers were held, discussing various aspects of what had been learned from the interviews; these informed additional concept mapping and coding processes. An example would be the development of a perspective on what the management and organization research community can learn from the NLs (Dörfler \& Eden, 2013).

\section{Mapping the Findings}

Using the different map views in DE was, of course, also useful for writing up the findings from various perspectives - it made it possible to draw boundaries, and also develop links to the work of other researchers and writers. Another application of DE maps in this later stage was, for instance, to take a concept map created about the cognition of strategists and find similarities between their thinking and that of the NLs - so we can see what the interviews with NLs can teach us about the manager as strategist. That way, for instance, we have found parallels between knowledge gained in strategy-making workshops and knowledge generated in hot spots of scientific research.

As indicated earlier, the method above was not developed ex ante but emerged during the process of trying to understand what we have learned from the interviews. In the current research this method was not intended to be used specifically for investigating intuition but more generally for exploring the cognitive complexity of the interviewees. However, it seems likely that the same method would be applicable for research specifically aimed at intuition, and also to management and organization research in general; the fact that intuition emerged 
as one of the salient properties of a high level of cognitive complexity seems to support this claim.

\section{CONCLUSION}

When reporting on management and organizational research, and the methodology employed, we normally do not admit to intuition playing an important role. If we assume that management and organization researchers are similar to researchers in other fields, we must assume that the intuition-analysis cycle is, or should be, present in our research as well, and, indeed, might enhance it. However, the role of intuition, when used, is virtually never acknowledged explicitly, and intuition is unlikely to be discussed in research methodology programmes. Perhaps we undervalue the role of intuition in prosecuting good management and organization research. In this study we have presented a way of data processing that captures the richness of unstructured interviews and also allows for a formalised presentation that explicitly acknowledges intuition and its role in the research process rather than denying it. Using intuition and admitting that we do so could help in avoiding the darkest of Bergson's (1911: 267) prophecies: 'A different evolution might have led to a humanity either more intellectual still or more intuitive. In the humanity of which we are a part, intuition is, in fact, almost completely sacrificed to intellect.'

\section{REFERENCES}

Agor, W. H. 1986. The logic of intuitive decision making: A research-based approach for top management. New York: Quorum Books. 
Akinci, C., \& Sadler-Smith, E. 2012. Intuition in management research: A historical review. International Journal of Management Reviews, 14(1): 104-122.

Barnard, C. I. 1938. The functions of the executive. Cambridge, MA: Harvard University Press.

Behling, O., \& Eckel, N. L. 1991. Making sense out of intuition. The Academy of Management Executive, 5(1): 46-54.

Bergson, H. 1911. Creative evolution. New York: Henry Holt and Company.

Bergson, H. 1946. The creative mind: An introduction to metaphysics. New York: Citadel Press.

Beveridge, W. I. B. 1957. The art of scientific investigation, 2nd edn. Caldwell, NJ: Blackburn Press.

Bruner, J. S. 1966. On knowing: Essays for the left hand. New York: Atheneum.

Bruner, J. S. 1977. The process of education, 2nd edn. Cambridge, MA: Harvard University Press.

Bryson, J. M., Ackermann, F., Eden, C., \& Finn, C. B. 1996. Critical incidents and emergent issues in the management of large scale change effects. In D. F. Kettl, \& H. B. Milward (Eds.), The state of public management: 267-285. Baltimore, MD: Johns Hopkins University Press.

Bryson, J. M., Ackermann, F., Eden, C., \& Finn, C. B. 2004. Visible thinking: Unlocking causal mapping for practical business results. Chichester, UK: John Wiley \& Sons.

Corley, K. G., \& Gioia, D. A. 2011. Building theory about theory building: What constitutes a theoretical contribution? Academy of Management Review, 36(1): 12-32.

Csíkszentmihályi, M. 1997. Creativity: Flow and the psychology of discovery and invention. New York: HarperCollins. 
Csíkszentmihályi, M. 2002. Flow: The psychology of optimal experience, 2nd edn. London: Rider.

Dane, E., \& Pratt, M. G. 2007. Exploring intuition and its role in managerial decision making. Academy of Management Review, 32(1): 33-54.

Dane, E., \& Pratt, M. G. 2009. Conceptualizing and measuring intuition: A review of recent trends. In G. P. Hodgkinson, \& J. K. Ford (Eds.), International Review of Industrial and Organizational Psychology, Vol. 24: 1-40. Chichester, UK: Wiley.

Davenport, T. H., \& Prusak, L. 2000. Working knowledge: How organizations manage what they know, paperback edn. Boston, MA: Harvard Business School Press.

Dean, D., \& Mihalasky, J. 1974. Executive ESP. Englewood Cliffs, NJ: Prentice Hall.

Devinney, T. M., \& Siegel, D. S. 2012. Perspectives on the art and science of management scholarship. Academy of Management Perspectives, 26(1): 6-11.

Dörfler, V., \& Ackermann, F. 2012. Understanding intuition: The case for two forms of intuition. Management Learning, 43(5): 545-564.

Dörfler, V., \& Eden, C. 2013. Nobel Laureates: Implications for management and organization research. Paper presented at AoM 2013, the Seventy-third Annual Meeting of the Academy of Management, Lake Buena Vista, Orlando, Florida.

Dörfler, V., \& Stierand, M. 2009. Investigating the extraordinary. Paper presented at BAM 2009, the Twenty-third Annual Conference of the British Academy of Management, Brighton, UK.

Dörfler, V., Baracskai, Z., \& Velencei, J. 2009. Knowledge levels: 3-D model of the levels of expertise. Paper presented at AoM 2009, the Sixty-ninth Annual Meeting of the Academy of Management, Chicago. 
Eden, C. 1992. On the nature of cognitive maps. Journal of Management Studies, 29(3): 261265.

Eden, C. 2004. Analyzing cognitive maps to help structure issues or problems. European Journal of Operational Research, 159(3): 673-686.

Eisenhardt, K. M. 1989. Building theories from case study research. Academy of Management Review, 14(4): 532-550.

Flanagan, J. C. 1954. The critical incident technique. Psychological Bulletin, 51(4): 327-358.

Ford, C. H. 1977. The 'elite' decision-makers: What makes them tick? Human Resource Management, 16(4): 14-20.

Gardner, H. 1993. Creating minds: An anatomy of creativity seen through the lives of Freud, Einstein, Picasso, Stravinsky, Eliot, Graham, and Gandhi. New York: Basic Books.

Gardner, H. 1995. Leading minds: An anatomy of leadership. London: HarperCollins.

Gardner, H. 1997. Extraordinary minds: Portraits of exceptional individuals and an examination of our extraordinariness. London: Phoenix.

Glaser, B. G. 1992. Basics of grounded theory analysis: Emergence vs forcing. Mill Valley, CA: Sociology Press.

Glaser, B. G., \& Strauss, A. L. 1967. The discovery of grounded theory: Strategies for qualitative research. Chicago: Aldine Publishers.

Gore, J., \& Sadler-Smith, E. 2011. Unpacking intuition: A process and outcome framework. Review of General Psychology, 15(4): 304-316.

Gremler, D. D. 2004. The critical incident technique in service research. Journal of Service Research, 7(1): 65-89. 
Hadamard, J. 1954. The psychology of invention in the mathematical field. New York: Dover Publications.

Hodgkinson, G. P., Maule, A. J., \& Bown, N. J. 2004. Causal cognitive mapping in the organizational strategy field: A comparison of alternative elicitation procedures. Organizational Research Methods, 7(1): 3-26.

Hodgkinson, G. P., Langan-Fox, J., \& Sadler-Smith, E. 2008. Intuition: A fundamental bridging construct in the behavioural sciences. British Journal of Psychology, 99(1): 127.

Hodgkinson, G. P., Sadler-Smith, E., Sinclair, M., \& Ashkanasy, N. M. 2009. More than meets the eye? Intuition and analysis revisited. Personality and Individual Differences, 47(4): $342-346$.

Hogarth, R. M. 2001. Educating intuition. Chicago: University of Chicago Press.

Hong, F. 2006a. The enigma of human creativity: Hidden messages from Nikola Tesla's Moji Pronalasci. In R. J. Halaši, I. P. Ćosić, \& T. J. Halaši (Eds.), Naš Tesla (Our Tesla), Technical Science Monograph No. 18: 127-176. Novi Sad, Serbia: Faculty of Technical Science, University of Novi Sad and Society for the Promotion of Science Novi Sad.

Hong, F. 2006b. Tesla composed like Mozart, Celebration of the 150th anniversary of the birth of Nikola Tesla. Belgrade, Serbia: Department of Machine Engineering, Faculty of Engineering, University of Belgrade.

Huff, A. S. 1990. Mapping strategic thought. New York: Wiley.

Isaack, T. S. 1978. Intuition: An ignored dimension of management. Academy of Management Review, 3(4): 917-922. 
Isenberg, D. J. 1984. How senior managers think. Harvard Business Review, 62(6): 81-90.

Kahneman, D. 2003. A perspective on judgment and choice: Mapping bounded rationality. American Psychologist, 58(9): 697-720.

Kahneman, D., \& Klein, G. 2009. Conditions for intuitive expertise: A failure to disagree. American Psychologist, 64(6): 515-526.

Klein, G. 2004. The power of intuition: How to use your gut feelings to make better decisions at work, paperback edn. New York: Doubleday Currency.

Klein, G., \& Weick, K. E. 2000. Decisions: Making the right ones. Learning from the wrong ones. Across the Board, 37(6): 16-22.

Leavitt, H. J. 1975. Beyond the analytic manager (Part II). California Management Review, 17(4): 11-21.

Lee, N. J., \& Lings, I. 2008. Doing business research: A guide to theory and practice. Thousand Oaks, CA: Sage.

Maslow, A. H. 1970. Religions, values, and peak-experiences. New York: Penguin.

Maslow, A. H. 1971. The farther reaches of human nature. London: Penguin Compass.

Mintzberg, H. 1976. Planning on the left side and managing on the right. Harvard Business Review, 54(July-August): 49-57.

Osbeck, L. M. 2001. Direct apprehension and social construction: Revisiting the concept of intuition. Journal of Theoretical and Philosophical Psychology, 21(2): 118-131.

Peters, T. J., \& Waterman, R. H. J. 1982. In search of excellence: Lessons from America's bestrun companies. London: Profile Books.

Poincaré, H. 1914. Science and method. London: Thomas Nelson and Sons. 
Polányi, M. 1962. Personal knowledge: Towards a post-critical philosophy. London: Routledge.

Polányi, M., \& Prosch, H. 1977. Meaning, paperback edn. Chicago: University of Chicago Press.

Popper, K. R. 1968. The logic of scientific discovery, 2nd edn. London: Routledge.

Prietula, M. J., \& Simon, H. A. 1989. The experts in your midst. Harvard Business Review, 67(January-February): 120-124.

Sadler-Smith, E. 2008. Inside intuition. London: Routledge.

Salas, E., Rosen, M. A., \& DiazGranados, D. 2010. Expertise-based intuition and decision making in organizations. Journal of Management, 36(4): 941-973.

Simon, H. A. 1987. Making management decisions: The role of intuition and emotion. The Academy of Management Executive, 1(1): 57-64.

Sinclair, M. 2011. An integrated framework of intuition. In M. Sinclair (Ed.), Handbook of intuition research: 3-16. Cheltenham, UK and Northampton, MA, USA: Edward Elgar.

Sinclair, M., \& Ashkanasy, N. M. 2005. Intuition: Myth or a decision-making tool? Management Learning, 36(3): 353-370.

Sinclair, M., \& Coget, J.-F. 2011. Intuition in organizations. Symposium organized at AoM 2011, the Seventy-first Annual Meeting of the Academy of Management, San Antonio, Texas.

Thomas, A. B. 2004. Research skills for management studies. London: Routledge.

Tsoukas, H. 2005. Complex knowledge: Studies in organizational epistemology. Oxford: Oxford University Press.

Vaughan, F. E. 1979. Awakening intuition. New York: Anchor Books. 